\title{
EDITORIAL
}

\section{The Skeleton in the Closet: Harvesting a Skeletonized IMA}

\author{
Curt Tribble, MD
}

Division of Thoracic and Cardiovascular Surgery, University of Virginia Health System, Charlottesville, Virginia, USA

\section{MULTIPLE ARTERIAL GRAFTS INCREASE SURVIVAL}

People seldom do what they believe in. They do what is convenient, then repent. - Bob Dylan

There is a considerable amount of data that using more than one arterial graft provides a survival advantage for patients undergoing coronary bypass operations. The Society of Thoracic Surgeons has a set of official guidelines for the use of arterial grafts, which include the following recommendations [Aldea 2016]:

- Internal mammary arteries (IMAs) should be used to bypass the left anterior descending (LAD) artery when bypass of the LAD is indicated.

- $\quad$ As an adjunct to left internal mammary artery (LIMA), a second arterial graft (right IMA or radial artery [RA]) should be considered in appropriate patients.

- Use of bilateral IMAs (BIMAs) should be considered in patients who do not have an excessive risk of sternal complications.

- To reduce the risk of sternal infection with bilateral IMAs, skeletonized grafts should be considered, smoking cessation is recommended, glycemic control should be considered, and enhanced sternal stabilization may be considered.

- Use of arterial grafts should be a part of the discussion of the heart team in determining the optimal approach for each patient.

\section{WHY IS THERE A LACK OF ENTHUSIASM FOR} USING BOTH IMAS?

Do the right thing. It will gratify some people and astonish the rest. - Mark Twain

Despite the evidence of the survival benefit of using more than one arterial graft, the percentage of patients in the U.S. that are treated with more than 1 IMA currently is in single digits. [LaPar 2015]. It is hard to think of another realm of cardiothoracic surgery in which practitioners so often avoid evidence-based recommendations [Gaudino 2015]. However, there are a number of somewhat understandable reasons that the enthusiasm for using both IMAs has been limited,

Correspondence: Curt Tribble, MD, Professor of Cardiothoracic Surgery, University of Virginia Health System, Division of Thoracic and Cardiovascular Surgery, Box 800679, Charlottesville, VA, 22908; 434-243-9250 (e-mail: CGT2E@bscmail.mcc.virginia.edu). including the generally reported higher rates of sternal healing problems and infection. There is, indeed, considerable evidence that taking down both internal mammary arteries (IMAs) leads to an increased risk of wound healing and infection. There are numerous articles on risks of sternal wound problems associated with the use of both IMAs. In addition to impaired healing and the increased risk of infection they include pain, numbness, and respiratory compromise.

Furthermore, there are additional reasons for a reluctance to use the right internal mammary artery (RIMA), including the belief that the RIMA might not perform quite as well as the left internal mammary artery (LIMA) for various, somewhat valid reasons, including the facts that the RIMA:

- often bifurcates earlier than the LIMA (and may be, therefore, shorter).

- $\quad$ is further from potential targets, which leads to concerns about stretching the graft, choosing a suboptimal target site, and crossing the midline.

- takes extra time to take down, which inevitably prolongs the operation, at least slightly.

\section{WHAT IF THERE WERE WAYS TO OVERCOME}

\section{DRAWBACKS OF A SECOND IMA?}

There are ways to overcome these drawbacks, including:

- Skeletonization of the IMAs, which lessens impact on sternal healing and chest wall function.

- $\quad$ Y grafts (or sewing a free IMA to a vein hood), which expands potential targets.

- IMAs can be significantly dilated with topical agents.

- There are techniques to securely close the sternotomy.

- One can getup to speed on the techniques of skeletonization.

\section{WHAT ARE THE POTENTIAL ADVANTAGES OF} SKELETONIZING THE IMA?

How do I love thee? Let me count the ways. —Elizabeth Barrett Browning, 1806-1861

- Skeletonized IMAs dilate better, resulting in longer, larger grafts and increasing target options (site of graft, sequential grafting, etc), as well as making anastomoses technically easier, with grafts that have dilated.

- Skeletonization may be accomplished more quickly than the pedicled technique.

- $\quad$ Skeletonization may be even safer for the IMA than taking it in a pedicled fashion.

- Skeletonized IMA takedown has less impact on blood 
supply to the sternum, which leads to better healing and less infection.

- There is less numbness of the anterior chest wall with skeletonized IMAs [Markman 2010].

- There may be less chest wall bleeding.

Two very significant advantages of the skeletonized technique are that the IMA seems to end up being about half again as long and as large as a pedicled IMA, and it, therefore, handles more like a vein or a radial than the small IMA that often results when it is harvested in a pedicled fashion. Obviously, the longer length means it can reach more targets, including using the right internal mammary artery (RIMA) for the upper left lateral wall vessels (by passing it under the aorta and pulmonary artery through the transverse sinus) or for the distal RCA. This longer length also means that you will be less likely to find yourself saying, "well, we have taken the IMA down, so we must use it, even if we have to graft a vessel at a more diseased site than we would like, since we don't have the length to reach the ideal site." This push to graft a suboptimal site or to have more tension on the IMA than is optimal may be one reason the RIMAs seem to not be as good as LIMAs in many reports.

\section{Fast is good, but accuracy is everything. - Wyatt Earp}

Another potential advantage is that taking an IMA down in a skeletonized fashion may be faster than when harvested in a pedicle, at least once one becomes facile with this technique. Many of those who use this technique routinely claim that they can take an IMA down faster this way than they can when taking it as a pedicle. These advocates of skeletonization say that once you have done an IMA takedown like this 2 or 3 times, you'll be unlikely to go back to the pedicled technique.

Another commonly expressed concern with using the skeletonized technique is that it may make the IMA more vulnerable to injury or make it less optimally functional for some reason. However, there is good evidence that these concerns are unwarranted. For instance, Mats Dreifaldt, from the Karolinska Institute, Solna, Sweden, presented a paper at the 2017 AATS meeting, showing no difference in injury or subsequent flow through IMAs taken down in a skeletonized manner [Dreifaldt 2017]. Similarly, Ali et al note in a review of available reports, "in the four comparative studies, skeletonization patency was at least comparable to pedicled conduits and, in two studies, even higher. Patency was assessed with the use of angiography, performed on average within four years of CABG surgery. Patency rates exceeded $95 \%$ in the 10 non-comparative studies where angiographic follow-up was within three years of surgery. This is an important finding because it justifies further use of the skeletonized technique for CABG surgery. It also adds to a growing field of evidence that skeletonized IMA grafts are preferable to pedicled grafts because they may cause a lesser degree of devascularization of the sternum and, consequently, a reduction of sternal wound infection. The evidence presented here demonstrates that in terms of patency, skeletonized...left internal thoracic arteries provide excellent patency rates" [Ali 2010].

It is important to understand the anatomy of the

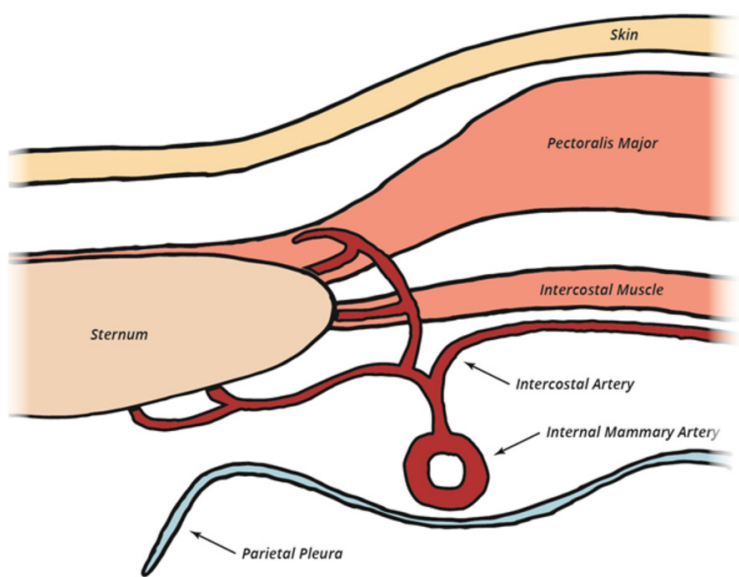

Figure 1. The IMA is attached to the intercostal by small branches, sometimes erroneously called perforators. This figure shows how the IMA hangs below the intercostal, which allows the preservation of the terminal portion of the intercostal artery when taking down an IMA in a pedicled fashion.

connections between the intercostal arteries and the IMA, as this understanding is crucial to maintaining blood flow to the sternum. Though somewhat variable, interspace by interspace, the basic anatomy is shown in Figure 1. Note that the IMA is not connected directly to the intercostal artery. The communication between these arteries occurs through small branches, which are sometimes called (though, perhaps, a bit inaccurately) perforators.

Finally, it seems reasonable to consider adopting the skeletonized technique, even when only one IMA is to be used in an operation, with the goal of becoming facile with the technique, not only so that it can be used reliably if both IMAs are to be taken down, but also because the advantages of skeletonization, such as better healing and less chest wall numbness, will also accrue even when only one IMA is used.

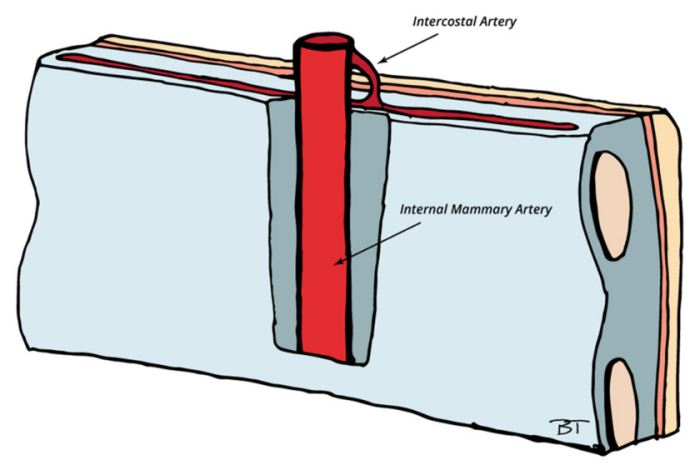

Figure 2. This diagram illustrates how the arterial connections between the IMA and the intercostal arteries are both small and fairly long, facilitating their division between clips. 


\section{SETTING UP FOR THE IMA TAKEDOWN}

It's supposed to be hard. If it wasn't hard, everyone would do it. The hard is what makes it great. - Tom Hanks in "A League of Their Own"

First of all, put your concerns about difficulty aside because taking down a skeletonized IMA is not harder than taking it as a pedicled graft. It might even be easier, especially when this technique is used routinely.

Before starting to take down the internal mammary artery (IMA), you must open the sternum, of course. As is true in most surgical incisions, you should remember the old surgical axiom that one should "open while thinking about closing." It is good to free the undersurface of the abdominal fascia of the properitoneal fat as soon as the sternotomy has been done and periosteal bleeding is controlled. It is important to do this at some point, and it is most easily done at this juncture. Cleaning the fat off the underside of this fascia makes closing this part of the incision easier, and it also facilitates the safe placement of chest tubes and pacing wires, as one can keep the fat, and, thus, the peritoneum posterior to the space through which the tubes and wires will run, protected. Clearing this properitoneal fat off the rectus fascia also allows a bit of this properitoneal fat to be available for coverage of the heart with the flap which will be described below.

After getting the sternal retractor in, the next step should be to create a Flege Flap. Dr. John Flege described this very useful technique [Flege 1987].

Reasons to use this flap include the facts that it provides:

- A good path into the pericardium for the LIMA to reach the LAD.

- Coverage of the LIMA, and the RIMA as well, if it is used.

- Protection of the right ventricle (RV).

- (Remember: every patient is at risk of needing a reoperation sooner or later, so keeping the RV away from the sternum is always desirable.)

To create this flap, you should mobilize and keep in continuity any pleural, pericardial, and properitoneal fat available to help with later coverage of the RV, starting as far to the right as you can and developing this flap of fat towards the left. You should dissect all this soft tissue from the anterior surface of the pericardium fairly far over to the left and leave it connected there so that it can be stitched back to the cut edge of the pericardium to position these tissues loosely over the RV and all the grafts, keeping them all well away from the sternum.

Do not open the left pleura if you don't have to. (If you do, leave the hole or holes fairly small, because this helps keep blood from pooling in the pleural space during the case.) In fact, you can usually push the left pleura down gently from the posterior chest wall with your thumb or a sponge stick, which helps to mobilize more of the pleural fat on the left side so that it will be available for the eventual coverage of the right ventricle, and pulling this pleura off the back of the chest wall also helps to expose the IMA, at least to some degree.

You should consider opening the pericardium at this point, so that you can have immediate access to go on bypass, if necessary, and so that you can get some idea of what the coronary targets look like (as well as how long the grafts need to be). Open the pericardium as far to the left as feasible (as shown in Figure 3), while remaining cognizant of the location of the left phrenic nerve. This flap of pericardium will become the principal part of the Flege flap. Creating this flap also allows a direct, comfortable trajectory of the IMAs to their eventual targets. Furthermore, this flap will insure that the RV and both IMAs will be quite unlikely to become adherent to the sternum at any point. Finally, opening the pericardium seems to allow a bit more flexibility of the chest wall during the IMA takedown, which could decrease postoperative discomfort. Eventually, at the end of the case, the edge of the pericardium should be stitched to the flap of pericardial, pleural, and properitoneal fat, which will result in a tension-free coverage of the right ventricle and the grafts.

Place the Rultract IMA retractor (or the retractor of your choice) at this point. Consider placing the hooks on the lower sternum to lift the lower sternum up high and to keep the hooks out of your line of sight. You can use the upper hook on the manubrium on occasion if you need extra exposure there, but it is often advantageous to just lift the lower portion, at least at first. There is a great deal more flexibility of the inferior chest wall, while there is considerably less flexibility of the superior chest wall. It seems plausible that minimizing both the amount of lifting and the time spent pulling up on the manubrium may also lessen postoperative discomfort a bit.

It is generally helpful to have the anesthesiologists decrease the tidal volume being used to ventilate the lungs while working on the IMAs. With the tidal volume diminished, there is, of course, more space to work and less movement in the nearby lung.

\section{TAKING DOWN THE IMA}

At this point, look inside the chest and identify the IMA anywhere you can see the white streak of the IMA. Nick the endothoracic fascia just to the medial side of the IMA. Then hook a scissor, such as a Metzenbaum, in the small slit you have made and begin to cut the endothoracic fascia right on top of the artery. (Technically you'll be right on the



Figure 3. The Flege Flap. 
back or posterior surface of the IMA rather than on top of it.) Carry this initial incision in the fascia as far as you can, in each direction, while keeping the IMA in plain sight. It can be helpful to find a pair of Metzenbaum scissors that have blades that are curved a bit more than usual to use for this part of the exposure. The more curved the blades, the better. (Sometimes, operating rooms have instrument techs who can actually bend a pair of scissors for you.) One can also use the Bovie blade as a cold dissector, a technique that all who have taken down pedicled IMAs will be familiar with. One should try to minimize the amount of heat and electrical current applied to both the tissue around the IMA and near the intercostal bundles between the IMA and the sternal edge, as avoiding these damaging forces is the primary reason that taking down skeletonized IMAs lessens damage to the chest wall.

The IMA seems to be most reliably visible superiorly (ie, towards its origin). A pulse can usually be felt in the more exposed portions of the IMA. Usually it is covered by the endothoracic muscle (officially named the transversus thoracis muscle) in the mid portion of the chest, while reappearing more distally. The typical perivascular areolar tissue always forms a plane around the artery (sometimes called The Plane of Leriche). Remember that muscle doesn't bleed much. You can (and should) cut it with the scissors. Doing so will keep you from hurting the IMA with the Bovie.

You will usually be able to avoid hurting the pair of veins that run along either side of the IMA. These veins are not as close to the IMA as you might think. In fact, sometimes you don't even see them. But it doesn't really matter at all if you nick one or the other. Just clip them (or you can tie or oversew them, if that works better). Often pulling on the veins can aid in exposing the IMA, especially when you are first getting started with this dissection.

At this point, you can begin to use the Bovie as spatula. Again, you want to keep the coag setting at a very low level and to minimize its use. Almost no coag is needed for this technique. Clip and cut branches as they come into view. You should probably clip both sides. However, you can clip the IMA side, Bovie the chest side gently, and then cut the coagulated part. Again, do keep the Bovie on low power as some of its current can run into the IMA or an intercostal artery, which might harm these vessels. A way to protect the arteries during this type of coagulation is to hold the branch with forceps just above the clip. The forceps act, when used in this way, both as a heat sink and as an electrical ground, which is important, as heat or electrical current flowing into an artery can injure it. Remember too that coagulating up into the intercostal space may also injure the intercostal nerve, which can cause numbness, as well as the medial continuation of the intercostal artery, which can make the sternum ischemic. Again, it should be emphasized that the use of clips is preferred to optimize the value of this skeletonized technique and should be the default technique for controlling the IMA branches, on both sides, when feasible.

It may be helpful to put a vessel loop around the first segment of the IMA that separates from the chest wall. Use

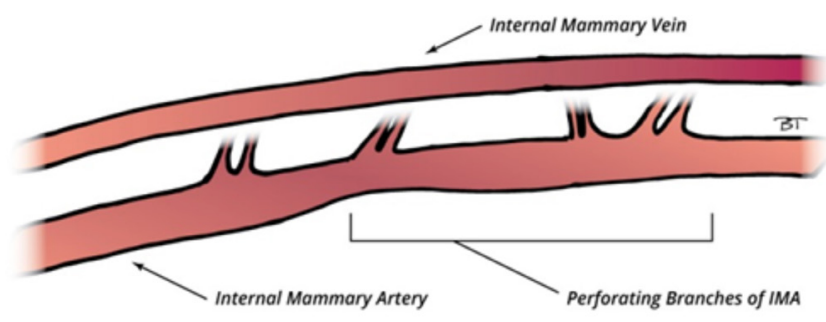

Figure 4. The branches of the IMA are smaller than one would imagine and are often multiple in each interspace.

a half of a loop (ie, cut the vessel loop in half). To keep the loop in place, put a clip or two on the vessel loop relatively near the IMA, which will make it easier to control. Slip that loop up and down the IMA as it frees up and drops down. This vessel loop allows gentle, safe pressure on the IMA to aid exposure. You must be very gentle when applying tension to the IMA as you dissect it free. You can use more than one loop if that seems useful. Take down all parts of the IMA that are easily visible first. Then you can join up the areas you have freed up, cutting through the thicker endothoracic fascia and muscle in the central part of the thorax at this point. Again, remember the plane of Leriche will allow you to dissect on the IMA underneath the muscle as you define where you can cut the muscle.

As noted earlier, the endothoracic muscle (like the anterior scalene muscle in a thoracic outlet operation) can be cut with scissors with minimal bleeding. You can use a right angle or a hemostat to develop the plane near the artery whenever you are unable to see the IMA through the fascia. That is, you can spread in the plane beneath the IMA to see what you need to cut to allow the IMA to fall away from the chest wall. And, you'll be surprised at how much the IMA begins to hang down, as it's dissected out and its branches are clipped and cut. Remember that there are no branches where the IMA is directly beneath a rib. The branches of the IMA go up (anterior) to join the intercostal arteries, which are on the superior side of the interspaces. It's helpful to remind yourself of these facts so that you can envision where those small IMA branches will be located. The more the IMA comes down the easier it is to continue the dissection. The IMA branches to the intercostals are smaller than you might have thought, most of the time. And they are much smaller than the vein branches encountered in standard IMA takedown as demonstrated in Figure 4.

You'll end up with a groove in the chest wall soft tissue that is quite narrow and has a technically satisfying appearance. That is, it will become apparent that you haven't butchered the chest wall during this dissection. This appearance is congruent with the data showing this technique of skeletonization is good for healing, reducing infection, decreasing numbness, and minimizing bleeding.

One ought to dissect the IMA up fairly high (superior) in the chest. This upper dissection is usually easier than the more distal portion, as there is more fat around the IMA in 
that area, and the veins are even further from it than they are more inferiorly. And, it's usually easier to see there, from the outset of your dissection, as noted earlier. Marasco has published a very well illustrated guide to these techniques [Marasco 2016].

Finally, one must be aware that nearly $50 \%$ of the time, the phrenic nerves cross over the IMAs high in the chest. That is, the phrenic nerves may be posterior to the IMA and thus potentially in harm's way, which is true whether taking the IMA in a skeletonized manner or as a pedicle [Owens 1994].

\section{DEALING WITH THE IMA AFTER SKELETONIZATION}

Once the IMA is dissected out and hanging free, but still connected at both ends, one can give a small amount of heparin ( 3,000 units) and then clip the IMA as far distally as feasible, which should be down near the xiphoid. You might consider not dividing the first IMA until you have taken down the second, if both are to be used, so that the small heparin dose can be given after both dissections are completed. Use a medium clip to clip the lower end of the IMA, not a bulldog, as this makes handling the IMA later less awkward. Clipping the IMA in this way allows the systemic blood pressure help to dilate the IMA while cannulation for bypass is carried out. The IMA should be squirted at this point (with a bit of pressure through a small 23-gauge needle) with nitroglycerine (NTG) and 4\% lidocaine. The nitroglycerine solution you want to use is the more concentrated version, which is $5 \mathrm{mg} / \mathrm{mL}$ and which will be in vials that are usually used to make up a nitroglycerine drip. This concentration should be available in the anesthesiologists' cart. It is best if these solutions don't get into the pleural space, should it be open, as these drugs can both be adsorbed systemically quite quickly from the pleural space, though not from the pericardial space. Leave the IMA wrapped in a sponge to keep it soaking in the NTG and lidocaine until you are ready to use it. Leave it as straight as possible, as it seems to dilate best when it is straight, while soaking in the vasodilators. Not everyone divides the IMA at this point, but it is likely optimal to do so, as it seems to dilate better, stay out of the way of the sternal retractor, and the IMA is easier to use when you're ready to sew it to a coronary (rather than having to work underneath the regular sternal retractor to divide the distal end of it later in the case).

Give the IMA the once over at this point to be sure that all branches are clipped. Occasionally, you'll end up having Bovied a branch or two during the takedown. The vasodilators may open such a branch up later and start some annoying bleeding. Looking for such branches should be done again prior to constructing the eventual anastomosis. It's probably best to just clip them all, at one point or another.

\section{CONSIDERATIONS FOR ROUTING (AND PROTECTING) THE RIMA, WHEN IT IS USED}

- Remember that every patient is a potential reop (early or late).

- Some route the RIMA behind the SVC (as this route may be the shortest distance to the heart for the RIMA).

- It can be routed through the transverse sinus, usually to high lateral wall vessels.

- It can be left in front, to graft the LAD. If this technique is used, consider running the RIMA through a Gortex graft, which may protect it, both early and later, or covering it in some other manner.

\section{CLOSING THE CHEST AFTER BILATERAL IMA TAKEDOWN: A FEW BRIEF CONSIDERATIONS}

The patient's outcome correlates directly with the surgeon's attention to a myriad of minor details. This obsession of doing a lot of little things right is the foundation for good surgical results. - Hiram C. Polk, MD

Besides skeletonizing the IMAs, optimal chest closure can optimize sternal wound healing and minimize the risk of infection. Concerns about sternal wound healing after bilateral IMA takedown are valid and substantiated by numerous reports, including the recent interim report from the ART trial [Taggart 2016]. Even though, as noted earlier, there is evidence that skeletonizing the IMAs can reduce the likelihood of sternal wound problems, it is still imperative that the sternum be closed securely, even when using the skeletonization technique.

There are a variety of strategies for optimizing sternal wound closure, including optimizing sternal fixation with wires or other closure systems, the proper closure of the fascia of the chest and upper abdominal fascia, management of the soft tissue space between the fascia and the skin, and the skin itself. Many surgeons believe that the expensive and somewhat complex closure systems are unnecessary if they adhere to certain principles for the management of each part of the sternal closure. An early proponent of the use of bilateral IMAs, Alfred Tector, described the technique of sternal closure that he found reliable in this setting, which involved the use of 12 wires, alternating wires placed in the interspaces that wrapped around the sternum with wires that were placed through the sternum itself [Tector 1994]. Others have also concluded that wires, or bands that encircle the sternum (described as peristernal wires or bands) create the strongest closures [Casha 2001].

However, many surgeons inappropriately give less attention to meticulous closure of the fascia of the chest and upper abdomen than of the sternum itself. Both the chest and abdominal portions of the trunk are surrounded by a continuous layer of strong fascia. Careful closure of this layer was said to be at least as important, if not more important, than the closure of the sternum itself by Andrew Morrow and his successors at the Surgery Branch of the National Heart, Lung, and Blood Institute (NHLBI) at the National Institutes of Health when the NHLBI training program for surgical associates was still in existence. The fascial closure technique used at the NHLBI emphasized the use of heavy sutures placed in an interrupted, figure of eight fashion in the upper abdominal fascia and between each sternal wire. Those placed in the presternal fascia were placed in a manner that has been described as digging into the periosteum of the sternum. Advocates of this strategy have said that it is actually as strong as, if not stronger than, the wire closure of the sternum. 
The potential space between the fascial closure and the skin, especially in heavy patients, is best dealt with by using suction drains rather than sutures, as the fat in this region has no capacity to hold sutures. A flat drain that can be attached to a bulb works well for this area. The skin should be closed meticulously with two layers of absorbable sutures, with the first being a deep dermal closure and the second being, usually, a subcuticular suture of monofilament absorbable material. This closure must be airtight, as the chest is the only negative pressure environment in the body, and any imperfection in the closure of the skin can result in air and accompanying skin flora being sucked into the wound. Many surgeons supplement this skin closure with a surgical adhesive or a negative pressure wound covering device. Finally, for women with large breasts, plastic surgeons familiar with reduction mammoplasty suggest that large breasts should be supported in some way, either with bras or, at least in the early postop period, with the use of an adhesive drape which can take all the tension off of the skin closure during the early postoperative period.

\section{CONCLUSION: THE SKELETON SHOULD BE ALLOWED TO COME OUT OF THE CLOSET}

I see no reason why I should be consciously wrong today because I was unconsciously wrong yesterday. - Supreme Court Justice Robert H. Jackson, 1945

It is quite clear that many patients undergoing coronary revascularization could benefit significantly from more than one arterial graft. Most, if not all, perceived reasons for not using both IMAs can be overcome with relatively straightforward alterations in standard techniques. Coronary surgeons should consider adopting the described techniques to expand the use of bilateral IMA grafts in selected cases. And, coronary surgeons should consider the use of the skeletonization technique even for single IMA cases, as this technique appears to be superior to the pedicled technique and because gaining facility with this technique will likely lead to increased use of bilateral IMA grafts in appropriate patients.

\section{REFERENCES}

Aldea G, Bakaeen F, Pal J, et al. 2016. The Society of Thoracic Surgeons Clinical Practice Guidelines on Arterial Conduits for Coronary Artery Bypass Grafting. Ann Thorac Surg 101:801-9.

Ali E, Saso S, Ashrafian H, Athanasiou T. 2010. Does a skeletonized or pedicled left internal thoracic artery give the best graft patency? Interact Cardiovasc Thorac Surg 10:97-104.

Casha A, Gauci M, Yang L, Saleh M, Kay P, Cooper G. 2001. Fatigue testing median sternotomy closures. Eur J Cardiothorac Surg 19:249-53.

Dreifaldt M, Taggart D, Bodin L, Geijer H, Liden M, Souza D. 2017. Comparable mid- and long-term patency rates for skeletonized and non-skeletonized internal thoracic artery grafts: a prospective randomized trial. http://aats.org/aatsimis/AATS/Meetings/Active_Meetings/ Centennial/Preliminary\%20Program/Monday_Controversies_in_ CABG_2017.aspx.
Flege J. 1987. Pericardial incision for IMA coronary bypass surgery. Ann Thorac Surg 44:424.

Gaudino M. 2015. The choice of conduits in coronary artery bypass surgery. J Am Coll Cardiol 66:1729-37.

LaPar D, Crosby I, Rich J, et al. 2015. Bilateral internal mammary artery use for coronary artery bypass remains underutilized: a propensity-matched multi-institutional analysis. Ann Thorac Surg 100:8-15.

Marasco S. 2016. Total arterial revascularization. Oper Tech Thorac Cardiovasc Surg 21:20-30.

Markman P, Rowland M, Leong J-Y, et al. 2010. Skeletonized internal thoracic artery harvesting reduces chest wall dysesthesia after coronary bypass surgery. J Thorac Cardiovasc Surg 139:674-9.

Owens WA, Gladstone DJ, Heylings DJ. 1994. Surgical anatomy of the phrenic nerve and internal mammary artery. Ann Thor Surg 58:843-4.

Taggart DP, Altman DG, Gray AM, et al, for the ART Investigators. 2016. Randomized trial of bilateral versus single internal-thoracic-artery grafts. N Engl J Med 375:2540-9.

Tector AJ, Amundsen S, Schmahl TM, Kress D, Peter M. 1994. Total revascularization with T grafts. Ann Thorac Surg 57:33-9

\section{ADDITIONAL ARTICLES ON OUTCOMES FOR BIMA GRAFTING}

Locker C et al. 2012. Multiple arterial grafts improve late survival of patients undergoing CABG: analysis of 8,622 patients with multivessel disease. Circulation 126:1023-30.

Taggart DP, Altman DG, Gray Ahmed AM, et al for the ART Investigators. 2010. Randomized trial to compare bilateral vs. single internal mammary coronary artery bypass grafting: 1 -year results of the Arterial Revascularisation Trial (ART). Eur Heart J 31:2470-81.

Weiss AJ, Zhao S, Tian DH, Taggart DP, Yan TD. 2013. A metaanalysis comparing bilateral internal mammary artery with left internal mammary artery for coronary artery bypass grafting. Ann Cardiothorac Surg 2:390-400.

\section{ADDITIONAL ARTICLES ON TECHNIQUES FOR SKELETONIZATION}

Dai C, Lu Z, Zhu H, Xue S, Lian F. 2013. Bilateral internal mammary artery grafting and risk of

sternal wound infection: evidence from observational studies. Ann Thorac Surg 95:1938-45.

Deo SV, Shah IK, Dunlay SM, et al. 2013. Bilateral internal thoracic artery harvest and deep sternal wound infection in diabetic patients. Ann Thorac Surg 95:862-9.

Ghazy T, Kappert U, Matschke K, Ouda A. 2014. ITA cold skeletonization: simplified step-by-step approach. CTSNet 2014 http://www.ctsnet. org/article/ita-cold-skeletonization-simplified-step-step-approach.

Gomes W, Paez R, Alves F. 2008. Surgical myocardial revascularization: off-pump use of bilateral internal thoracic artery grafting. Arq Bras Cardiol 90:18-23.

\section{ADDITIONAL ARTICLE ON TECHNIQUES FOR} OPTIMAL CLOSURE OF STERNOTOMIES

Tector AJ, Kress DC, Downey FX, Schmahl TM. 1996. Use of internal thoracic artery T-grafts for complete arterial revascularization. Op Techniques in Cardiac \& Thoracic Surgery 1:108-16. 